\title{
Erratum
}

\section{Acute effects of antidepressant drugs on long-term potentiation (LTP) in rat hippocampal slices}

\author{
Susanne Birnstiel ${ }^{1 *}$ and Helmut L. Haas ${ }^{1,2}$ \\ 1 Physiologisches Institut, Johannes-Gutenberg-Universtät, Saarstrasse 21, W-6500 Mainz, Federal Republic of Germany \\ 2 Physiologisches Institut, Heinrich-Heine-Universität, Moorenstrasse 5, W-4000 Düsseldorf 1, Federal Republic of Germany
}

Naunyn-Schmiedeberg's Arch Pharmacol (1991) 344:79-83

Figure 5 appears with the legend to Fig. 9 and vice versa; the legend are correctly positioned. In Fig. 9 the three traces represent 10,20 and $50 \mu \mathrm{M}$.

The correct figures and legends are printed below.

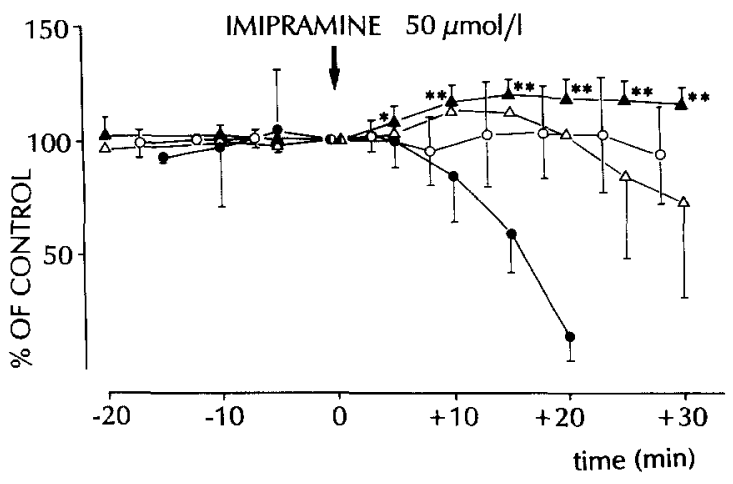

Fig. 5. Effect of imipramine $50 \mu \mathrm{mol} / 1$ on four different paradigms. Open circles: population spike in normal perfusion medium, $n=7$; closed circles: spontaneous bursting activity in low $\mathrm{Ca}^{2+}$-medium; closed triangles: first population spike in $\mathrm{Mg}^{2+}$ free medium; open triangles: third population spike in $\mathrm{Mg}^{2+}$-free medium, $n=7$. Arrow indicates the time of drug addition to the perfusion medium. Significantly different from control, $* P=0.05$; ${ }^{* *} P=0.02$, Wilcoxon signed ranks test for two related samples

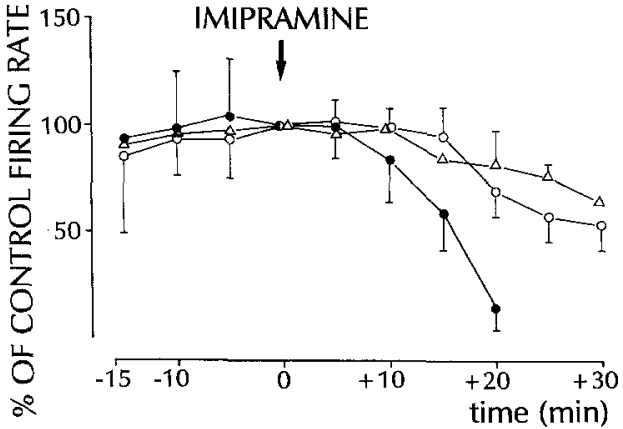

Fig. 9. Effect of different concentrations of imipramine on spontaneous bursting activity in low $\mathrm{Ca}^{2+}$-high $\mathrm{Mg}^{2+}$ medium. Open triangles: $10 \mu \mathrm{mol} / 1, n=6-3$; open circles: $20 \mu \mathrm{mol} / 1, n=3$; filled circles: $50 \mu \mathrm{mol} / 1, n=3$. Arrow indicates the time of drug addition to the perfusion medium 